\title{
EDITORIAL
}

\section{TREATMENT OF VENEREAL DISEASE IN MERCHANT SEAMEN}

The editorial of this Journal published in June 1943* was devoted to the treatment of venereal diseases in merchant seamen. That particular editorial was evoked by the " Recommendations of the Ministry of Health on the Treatment of Merchant Seamen " issued in March, 1943, whieh detailed the routine to be followed in cases of early syphilis treated ashore and in cases of gonorrhoea treated at sea. Whilst a benison was given to the intensive treatment of syphilis in seamen in clinics ashore, a more guarded attitude was adopted with regard to sulphonamide therapy of gonorrhoea afloat.

The very common practice of treatment before diagnosis could not be completely condemned, but apprehension about the probable neglect of adequate tests to exclude comtemporaneous infection with syphilis and to determine the cure of the gonorrhoea was expressed in these words :

The immediate treatment in civil clinics of gonorrhoea on clinical grounds alone but without pathological confirmation of the diagnosis would be reprehensible. On the other hand, the earlier the newer sulphonamides are used in such cases the more certain and speedy is the prospect of cure. Academic accuracy must give place to more urgent considerations. The danger is of inculcating a casual attitude to diagnosis, to tests of cure, and to serological exclusion of concomitant syphilitic infection. The expedient of to-day may become the accepted practice of to-morrow, and it would be regrettable if the present recommendations should lead to any general lowering of currently accepted standards.

Although it is rather more than 9 years since this editorial was published, it is as true to-day as it was then with the added menace of excessive penicillin therapy. The Penicillin (Merchant Ships) Act of 1951, sanctions the use of penicillin by nonmedical personnel, and in Amendment Number Four to the Ship Captain's Medical Guide (1946), a number of conditions as diverse as gumboils and gonorrhoea are described as suitable for the employment of penicillin injections. Instructions for the use of penicillin are clear, and special attention is paid to the need for giving the minimal dosage in cases of urethritis-200,000 units of procaine penicillin in aqueous suspension. Unfortunately, it is difficult to overcome the reluctance of a layman to examine an infected organ carefully, since the fear of contracting venereal disease through nonsexual contact is deeply ingrained. No instructions are given to examine the patient to exclude co-

\footnotetext{
* Eritish Journal of Venereal Diseases (1943). 19, 47.
}

existent primary syphilis although the possibility of purulent balano-posthitis is mentioned. Captains are asked to make smears from the urethra on slides by means of a match stick and to label these slides with the patient's name so that he may take them with him when he reports to a shore clinic, but in practice this is rarely, if ever, done, probably because of the fear of infection through handling infected objects. In spite of repeated injunctions on the correct use of penicillin in cases of urethritis, it is unfortunately true that failure to affect the character of the discharge results in multiple dosage with penicillin up to ten mega units in some cases.

Intermittent dosage makes the problem even more menacing in view of the serious consequences that may ensue in the case of a partially-treated undiagnosed early syphilis. It has to be recorded that not all the blame for excessive dosage of penicillin can be placed on non-medical shoulders, since clinics and practitioners overseas are prone to give further doses of penicillin as a routine for urethral discharge.

The management of syphilis is on sound lines in that diagnosis is placed in the hands of shore clinics, as is also treatment, except where a ship's surgeon is carried.

Improvement, therefore, remains to be sought in the treatment of urethritis. In Great Britain, of every five such cases, two are non-gonococcal and three are gonococcal or belong to the group of unspecified mixed gonococcal and non-specific infections. The exhibition of $1 \mathrm{~g}$. streptomycin in one single deep subcutaneous injection in $4 \mathrm{ml}$. sterile distilled water, followed by the advised treatment by sulphonamides, would do much to cure urethritis and yet leave no fear of syphilis d'emblée that has not always existed after venereal exposure. Chloramphenicol is carried in ships for the exclusive treatment of typhoid fever and there appears to be no reason why the much commoner and more easily diagnosed complaint of urethritis should not have its own specific in the shape of streptomycin, restricted to one dose of one gramme.

Further, there is no insuperable objection to the captain of the ship, or his responsible officer, furnishing a letter to accompany the patient on his first visit to a shore clinic, giving clear details of the drugs used, dosages, and relevant dates. A transfer book (V 15a or V 44) can then be prepared by the medical officer of the clinic and handed to the patient for his subsequent surveillance. 